\title{
IMPLEMENTASI GOOGLE MAPS API PEMETAAN JALUR EVAKUASI BENCANA ALAM DI KABUPATEM LOMBOK UTARA
}

\author{
Khaerul Yasin ${ }^{1}$, Ahmat Adil ${ }^{2}$ \\ ${ }^{1,2}$ Jurusan Ilmu Komputer Universitas Bumigora \\ JL. Ismail Marzuki Mataram, NTB, Telp (0370)-634 498, Fax (0370) 638369 \\ Email : ${ }^{1}$ khaerulyasin60@ gmail.com, ${ }^{2}$ ahmat.adil@universitasbumigora.ac.id
}

\begin{abstract}
ABSTRAK
Pada dasarnya, Indonesia dilalui oleh tiga lempeng tektonik aktif yakni Lempeng Indo-Australia di bagian selatan, dan Lempeng Eurasia di bagian utara serta Lempeng Pasifik di bagian Timur. Lempeng-lempengan tersebut saling bertumbukan karena pergerakan Lempeng Indo-Australia menunjam ke bawah lempeng Eurasia. Akibat tunbukan ini, menimbulkan gempa bumi, jalur gunungapi, dan sesar atau patahan di sebagian wilayah Indonesia. Dalam Sistem Informasi Geografis rute evakuasi akan digunakan Google maps Api untuk mengimplementasikan pembuatan peta spasial jalur evakuasi. Google Map Api merupakan aplikasi interface yang dapat diakses lewat javascript agar Google Map dapat ditampilkan pada halaman web yang sedang kita bangun. Hasil atau keluaran yang akan dicapai yaitu dihasilkannya Sistem informasi geografis pemetaan jalur evakuasi bencana alam di kabupaten lombok utara yang dapat dijalankan pada platform Web. Berdasarkan pada uji coba yang dilakukan maka dapat disimpulkan bahwa aplikasi ini dapat membantu masyarakat untuk menemukan lokasi jalur evakuasi dan titik kumpul sesuai dengan kecamatan dan kelurahan tempat tinggal masing-masing.
\end{abstract}

Keyword : SIG, Jalur Evakuasi, Titik Kumpul, Google Maps, GPS

\begin{abstract}
Basically, Indonesia is traversed by three active tectonic plates namely the Indo-Australian Plate in the south, and the Eurasian Plate in the north and the Pacific Plate in the east. The plates collide with each other because the Indo-Australian Plate movement drops below the Eurasian plate. As a result of this accumulation, it caused earthquakes, volcanoes, and faults or faults in parts of Indonesia. In the Geographic Information System evacuation routes will be used by Google maps Api to implement the spatial map making of evacuation routes. Google Map Api is an application interface that can be accessed via javascript so that Google Map can be displayed on the web page that we are building. The result or output to be achieved is the creation of a geographic information system mapping natural disaster evacuation route in the North Lombok district that can be run on a Web platform. Based on the trials conducted it can be concluded that this application can help the community to find the location of evacuation routes and gathering points in accordance with the districts and villages where they live.
\end{abstract}

Keyword: GIS, Evacuation Path, Gathering Point, Google Maps, GPS

Author Korespondensi (Ahmat Adil)

Email : ahmat.adil@universitasbumigora.ac.id

\section{PENDAHULUAN}

Dalam sejarahya, Indonesia adalah termasuk salah satu negara rawan bencana, dan terus melanda sepanjang masa. Disamping penyebanya adalah faktor alam yaitu gempa bumi, tsunami, tanah longsor, banjir dan gunung meletus juga disebabkan oleh faktor non alam seperti wabah penyakit dan kegagalan teknologi. Salah satu daerah yang sering dilanda bencana gempa bumi yaitu Provinsi Nusa Tenggara Barat dan khususnya di Kabupaten Lombok Utara.[1]

Dari sisi Geologi, wilayah Negara republik Indonesia dilalui oleh pertemuan tiga lempeng tektonik yang masih aktif yakni dibagian selatan adalah lempeng IndoAustralia,dan dibagian utara adalah lempeng Eurasia serta pada bagian timur adalah lempeng Pasifik. Pergerakan Lempeng-lempeng tersebut menyebabkan lempeng Indo-Australia 
menunjam ke bawah lempeng Eurasia sehingga menyebabkan gempa bumi, dan jalur gunung api, serta sesar yang sering juga disebut patahan. Dengan bergerak relative ke utaranya Penunjaman lempeng Indo-Australia serta dengan bergerak ke selatannya lempeng Eurasia, mengakibatkan terjadinya gempa bumi dan rangkaian gunungapi aktif sepanjang jalur penunjaman kedua lempeng yang sejajar yaitu Pulau Sumatera, Jawa, Bali dan Nusa Tenggara.[2]

$B N P B$ tahun 2008, dalam Pedoman Penyusunan Rencana Penanggulangan Bencana pada pilihan tindakan penangulangan bencana disebutkan mengenai kesiapsiagaan. Dalam kesiapsiagaan terdapat salah satu upaya yang dilakukan pada saat bencana mulai teridentifikasi yaitu dengan mendukung tugas kebencanaan melalui penyiapan sistem informasi dan komunikasi yang cepat dan terpadu.[2]

Latar belakang pembuatan sistem informasi ini adalah merujuk pada bencana yang terjadi di Pulau Lombok khususnya di Kabupaten Lombok Utara yang memakan banyak korban dan membuat kerugian pada masyarakat dan pemerintah Kabupaten Lombok Utara. Oleh karena itu perlu adanya mitigasi bencana yaitu berupa jalur evakuasi sebelum bencana atau saat terjadinya bencana. Jalur evakuasi ini akan memudahkan masyarakat untuk menghindari bencana yang akan terjadi di daerah Kabupaten Lombok Utara. Masyarakat memerlukan jalur ini agar pada saat terjadi bencana masyarakat dapat pergi ke tempat evakuasi dengan cepat serta melewati jalan yang benar sesuai dengan jalur evakuasi sehingga mengurangi resiko ancaman dan hal tersebut dapat mengurangi resiko jatuhnya korban jiwa jika bencana Gempa bumi yang berpotensi tsunami terjadi. [3]

Sistem inforamsi geografis (SIG) merupakan sistem informasi yang fungsinya dapat digunakan untuk memasukkan, menyimpan, memangil kembali, mengolah, menganalisis dan menghasilkan data dengan orientasi geografis, SIG memegang kemampuan untuk mengintegrasikan peta dengan detail informasi database dan gambar, serta mengubah peta biasa biasa menjadi peta pintar yang merespon queries dan membantu dalam analisis yang kompleks. [4]

Dalam Sistem Informasi Geografis jalur evakuasi akan digunakan Googlemaps Api untuk mengimplementasikan pembuatan peta spasial jalur evakuasi. GoogleMaps API adalah sebuah aplikasi interface dengan memanfaatkan javascript untuk dapat diakses pada Google Map untuk dapat ditampilkan pada halaman web yang dibangun. Google Map dapat diakses, dengan melakukan pendaftaran Api Key terlebih dahulu dan melakukan pendaftaran berupa nama domain web yang bangun. GoogleMaps API menyediakan 4 jenis pilihan model peta, yaitu : 1). untuk menampilkan peta biasa 2 dimensi (ROADMAP), 2). untuk menampilkan foto satelit (SATELLITE), 3). untuk menunjukkan relief fisik permukaan bumi dan menunjukkan seberapa tingginya suatu lokasi (TERRAIN), contohnya akan menunjukkan gunung dan sungai, 4). HYBRID akan menunjukkan foto satelit yang diatasnya tergambar pula apa yang tampil pada ROADMAP (jalan dan nama kota).

Dasar penggunaan Googlemaps dalam sistem informasi geografis jalur evakuasi ini ialah karena kemampuannya dalam menampilkan informasi yang lebih jelas dan lebih mudah di pahami bila di bandingkan dengan menggunakan peta vector atau digital.[5]

\section{Google Maps API}

Google Maps merupakan jasa peta globe virtual yang disediakan secara gratis dan online serta disediakan oleh Google yang dapat diakses di http://maps.google.com/. Google map API adalah ssebuah aplikasi interface dengan diakses melalui JavaScript supaya halaman web yang sedang dibangun dapat menampilkan Google Map. Supaya Google Map dapat diakses, maka diperlukan pendaftaran API Key terlebih dahulu dengan data pendaftaran berupa nama domain web yang dibangun.[6]

\section{METODOLOGI}

Model yang digunakan untuk pengembangan system, menggunakan Waterfall. Model Waterfall merupakan proses perencanaan, dengan semua proses kegiatan direncanakan dan dijadwalkan terlebih dulu sebelum dikerjakan.[7]

Adapun tujuan penulis mengadopsi model dari metode waterfall ini agar tahapantahapan dalam pembuatan perangkat lunak ini menjadi lebih terstruktur dan sistematik. Berikut adalah tahapan-tahapan yang penulis lakukan pada pengembangan sistem ini.[8] 
A. Tahap Analisys

1) Pengumpulan Data

- Studi Pustaka

Yang dilakukan pada tahap ini adalah membaca dan mempelajari referensireferensi yang relevan seperti buku, makalah, dan jurnal. Menggunakan fasilitas internet sebagai media untuk mencari data dan informasi yang di publikasikan. Beberapa teori pendukung utnuk memahami konsep antara lain, konsep aplikasi berbasis web, Google map, Geolocation, Google map API, Jalur Evakuasi, MySQL, PHP, dan pemodelan berupa UML

- Observasi

Tahap pengumpulan data dengan Observasi, penulis melakukan penelitian pada Badan Penanggulangan Bencana Daerah (BPBD) Kabupaten Lombok Utara dengan cara melakukan wawancara dan meminta data-data terkait dengan persebaran Jalur evakausi dan Titik Kumpul yang ada pada masing-masing Kecamatan di kabupaten Lombok utara.

\section{2) Identifikasi Masalah}

Berdasarkan hasil analisis dan informasi yang telah di jabarkan di atas mengenai prosedur pencarian jalur evakuasi di Kabupaten Lombok utara, di temukan beberapa hal sebagai kendala dari sistem, yaitu prosedural pencarian jalur evakuasi oleh masyarakat antara lain sebagai berikut :

1. Terbatasnya informasi mengenai mitigasi bencana khususnya mengenai jalur evakuasi bencana dan lokasi titik kumpul

2. Ketersediaan Data terkait jalur evakuasi yang blum tersedia secara keseluruhan di setiap kecamatan dan desa

3. Pengunjung kesulitan untuk mengetahui lokasi jalur evakuasi dan titik kumpul yang telah di tetapkan oleh Badan Penanggulangan Bencana Daerah (BPBD)

\section{3) Alternatif Solusi}

Didasarkan pada identifikasi masalah, maka permasalahan dapat diatasi dengan hal-hal sebagai berikut :

a) Dibutuhkan sistem pemetaan jalur evakuasi bencana dengan memanfaatkan google map Api untuk memudahkan masyarakat mencari informasi terkait jalur evakuasi b) Di perlukannya sistem yang memberikan informasi detail lokasi jalur evakuasi dan posisi titik kumpul sesui dengan data dari Badan Penanggulangan Bencana Daerah (BPBD)

c) Di perlukannya sistem yang akurat terkait lokasi jalur evakusi dan posisi Titik kumpul.

4) Analisis Kebutuhan

Untuk memperkirakan kebutuhan system yang baru maka diperlukan analsisi system, dengan cakupan sebagai berikut :

1. Perangkat Keras (Hardware)

Untuk mendukung pengoperasian program, maka diperlukan perangkat keras untuk menjalankannya. Perangkat tersebut harus memenuhi standar minimal kebutuhan hardware terhadap sistem yang akan di terapkan.

Spesifikasi standar yang dapat di gunakan untuk menjalankan sistem ini sehingga membuat sistem ini berjalan dengan kinerja yang optimal adalah sebagai berikut:

- $\quad$ Processor Intel $(\mathrm{R})$ core i5 8250U 3.4 $\mathrm{GHz}$

- $\quad$ RAM 4 GB

- Hardisk $1 \mathrm{~TB}$

- Mouse dan Keyboard

- Display NVIDIA GEFORCE 930 MX

2. Perangkat Lunak (Software)

Untuk menjalankan system, maka dibutuhkan beberapa perangkat lunak (softwere), yaitu sebagai berikut:

- Sistem operasi Microsoft windows 7/8/10

- Text editor yang di gunakan Sublime Text 3

- Browser yaitu Google chrome, Mozila Firefox atau Internet Explorer

- Bahasa pemrograman yaitu PHP dengan menggunakan Framework CodeIgniter

- Database yang di gunakan yaitu MySQL

- Webserver yaitu Apache

3. Pengguna (User)

Agar perangkat lunak berjalan dengan optimal dan baik, maka di perlukan beberapa pengguna di antaranya:

- Admin, sebagai pengguna yang akan menangani kebutuhan aplikasi (Server Control).

- Penguna (Masyarakat dan Pemerintah), yaitu orang yang akan menggunakan apliksi ini untuk mitigasi bencana, dan pencarian informasi terkait jalur evakuasi 
bencana alam di Kabupaten Lombok Utara.

\section{B. Tahap Design}

Pada tahap ini akan diterangkan mengenai Struktur Database, Entity Relationship Diagram (ERD), Class Diagram, Use case Diagram, Sequence Diagram, Activity Diagram, dan desain interface.[9]

1) Class Diagram

Disamping menunjukan hubungan antar class juga menggambarkan keadaan (atribut/property) suatu sistem, class diagram juga menawarkan layanan manipulasi keadaan tersebut[9] . Gambar berikut adalah contoh class diagram :
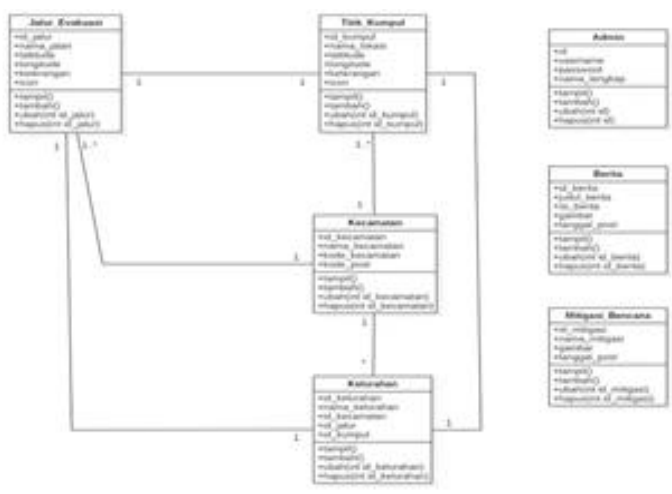

Gambar 1. Class Diagram

\section{2) Use Case Diagram}

Penggambaran aktivitas dengan urutan interaksi antara satu aktor atau lebih dengan suatu system [10]. Pada penelitian ini, rancangan usecase diagram memiliki 2 (dua) aktor yang berperan, yaitu administrator dan pengguna. Berikut tampilan dari use case dapat di lihat pada gambar berikut:

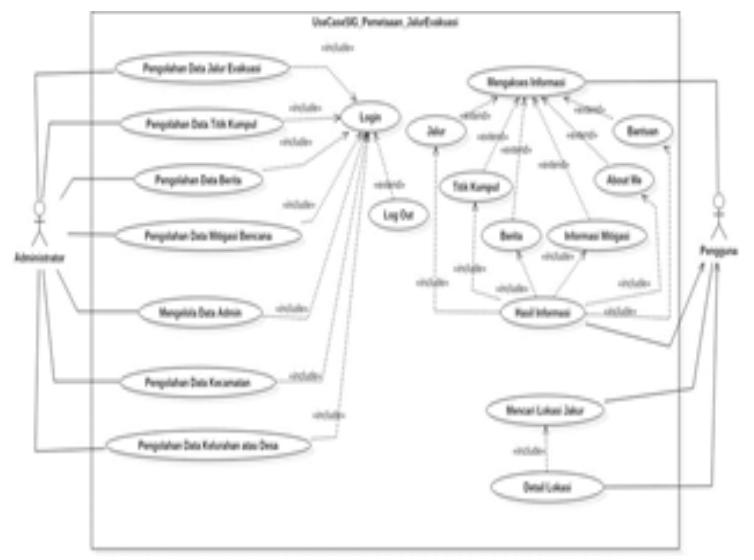

Gambar 2. Use Case Diagram
Keterangan:

1. Aktor yang berperan dalam sistem ini adalah administrator dan pengguna.

2. Include pada gambar artinya relasi use case tambahan ke sebuah use case di mana use case yang di tambahkan memerlukan use case ini untuk menjalankan fungsinya. Jadi untuk bisa melakukan proses manipulasi data seperti tambah, ubah dan hapus maka Administrator harus terlebih dahulu login. Sementara pengguna tidak perlu melakukan proses login.

5) Sequence Diagram

Untuk perancangan sistem, penggambaran sequence diagram[11] dilakukan utnuk menunjukan sistem yang sedang berjalan dengan Sequence Diagram Jalur Evakuasi, yaitu : Admin melakukan proses login dengan cara memasukkan username dan password kemudian data tersebut di cek dan di lakukan validasi setelah sukses maka Admin dapat melakukan pemambahan, pengubahan dan penghapuasan data Jalur Evakuasi.

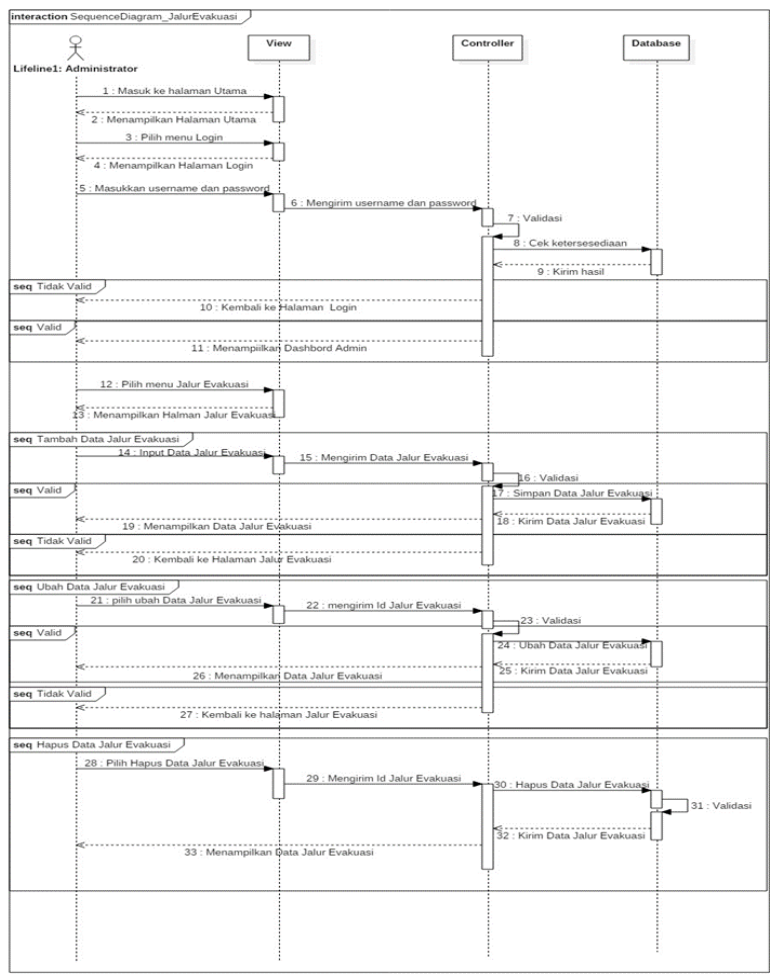

Gambar 3. Sequence Diagram Jalur Evakuasi

\section{6) Activity Diagram}

Activity diagram adalah alur kerja pada setiap use case. Adapaun activity diagram dalam penelitian ini adalah sebagai berikut :

a. Activity diagram Admin 


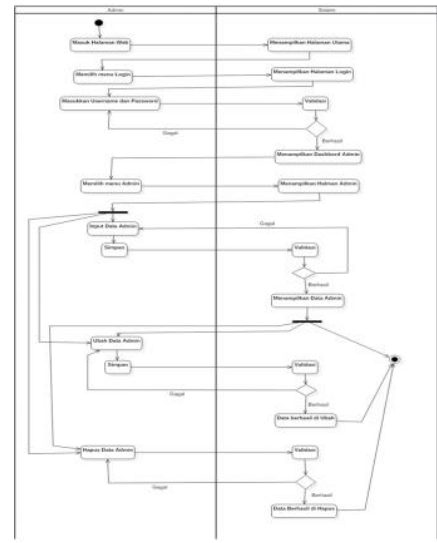

Gambar 4. Activity Diagram Admin

b. Activity diagram Jalur Evakuasi

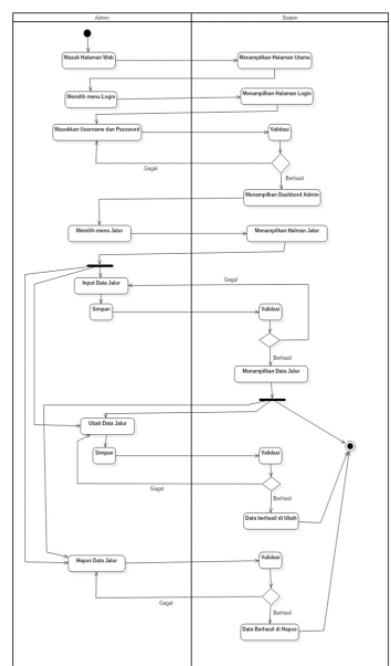

Gambar 5. Activity Diagram Jalur Evakuasi

7) Desain Interface

a. Halaman Utama

Halaman utama adalah halaman yang pertama kali muncul pada saat program pertama kali di jalankan. Pada halaman ini akan menampilkan beberapa informasi seperti peta yang akan menampilkan peta jalur evakuasi dan titik kumpul, kemudian form Pencarian yang bisa di gunakan oleh pengunjung untuk mencari lokasi jalur evakauasi dan titik kumpul sesuai kecamatan dan kelurahan yang di inginkan, kemudian ada Legenda yang menjelaskan tentang jalur evakuasi dan titik kumpul dan yang terakhir yaitu kolom komentar yang bisa di gunakan oleh pengunjung untuk menyampaikan komentar terkait dengan sistem.

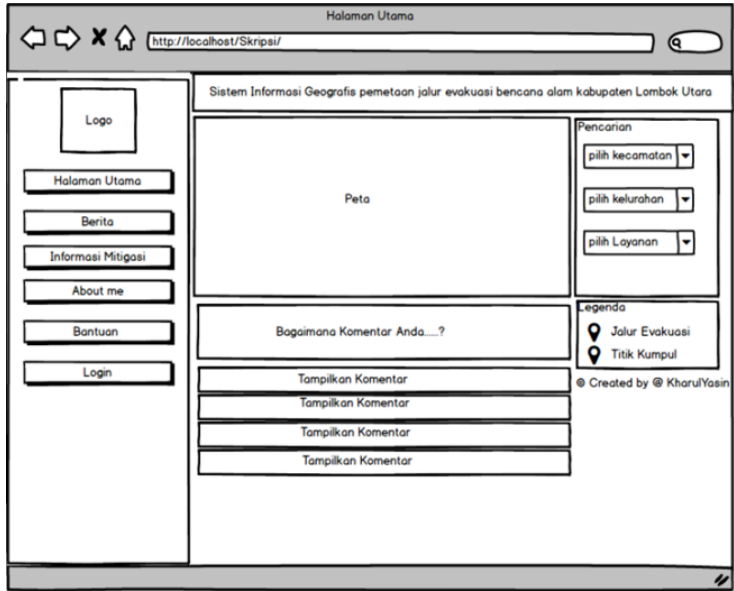

Gambar 6. Halaman Utama

b. Halaman Berita

Halaman Berita adalah halaman yang menampilkan tentang berita-berita terkait bencana dan penanggulangan-penganggulangan yang telah di lakukan pemerintah untuk mengatasi permasalahan bencana.

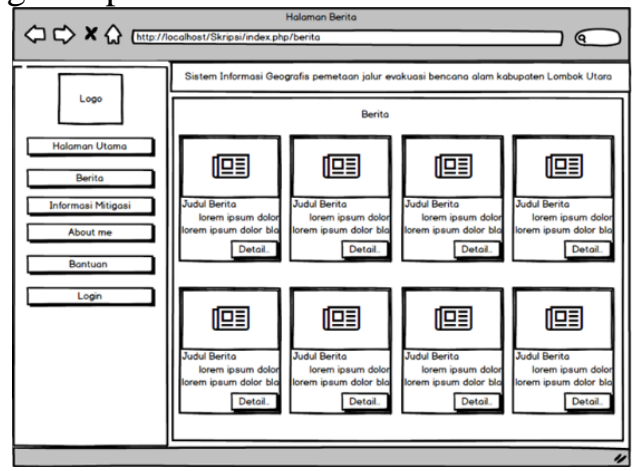

Gambar 7. Halaman Berita

c. Halaman Informasi Mitigasi

Halaman mitigasi bencana memberikan informasi mitigasi kepada masyarakat terkait tindakan yang harus di lakukan ketika tejadi bencana, informasi yang di tampilkan adalah dalam bentuk gambar sehingga lebih mudah untuk di pahami.

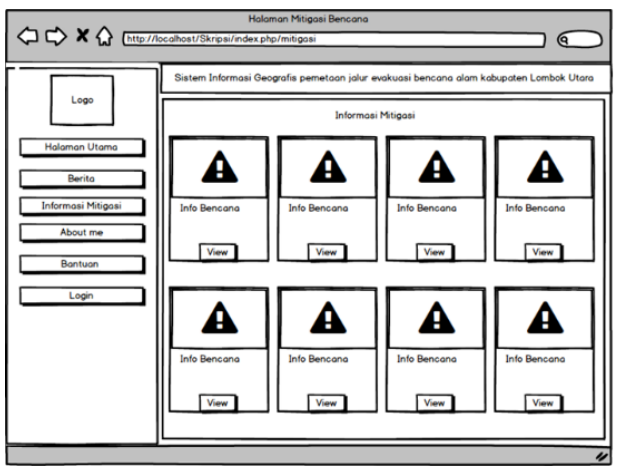

Gambar 8. Halaman Informasi Mitigasi 


\section{d. Halaman Dashbord Admin}

Halaman Dashbor Admin pertama muncul ketika Administrator berhasil login, pada halaman ini akan menampilkan data-data Administrator sehingga bisa di lakukan penambahan data, pengubahan dan penghapusan



Gambar 9. Halaman Dashbord Admin

e. Halaman Kecamatan

Halaman kecamatan adalah halaman yang menampilkan tentang data kecamatan yang ada di kabupaten Lombok utara

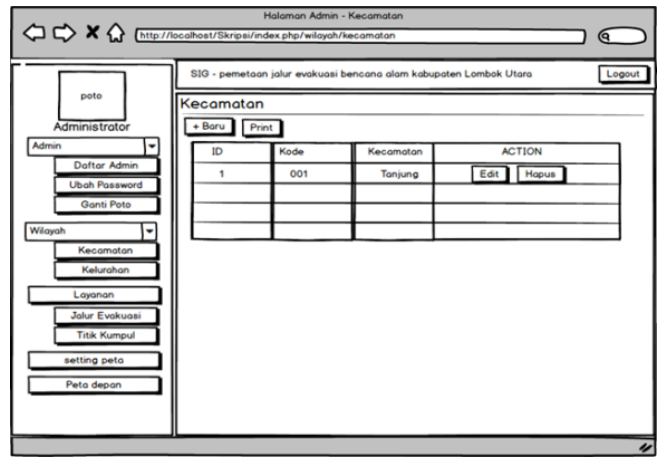

Gambar 10. Halaman Kecamatan

\section{f. Halaman Kelurahan}

Halaman kelurahan menampilkan tentang data-data keluarahan yang ada pada setiap kecamatan di kabupaten Lombok utara.

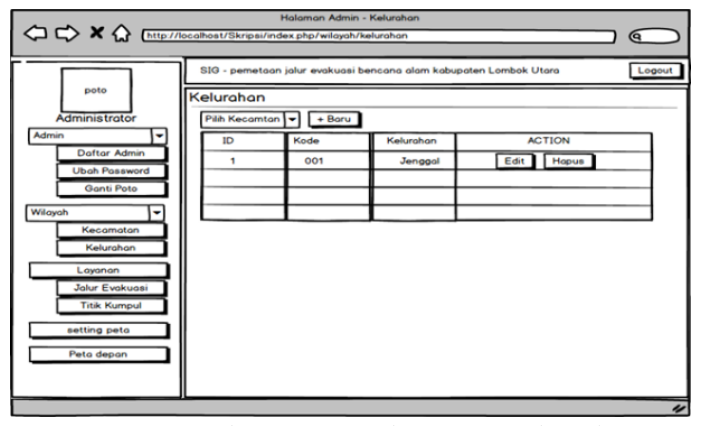

Gambar 11. Halaman Kelurahan g. Halaman Layanan (Jalur Evakuasi dan Titik Kumpul)

Halaman Layanan menampilkan tentang data-data jalur evakuasi dan titik kumpul, dimana dapat melakukan proses manipulasi data jalur evakuasi dan titik kumpul seperti penambahan data, pengubahan data dan penghapusan data sesuai dengan data-data yang telah di dapatkan ketika peneliti melakukan penelitian.

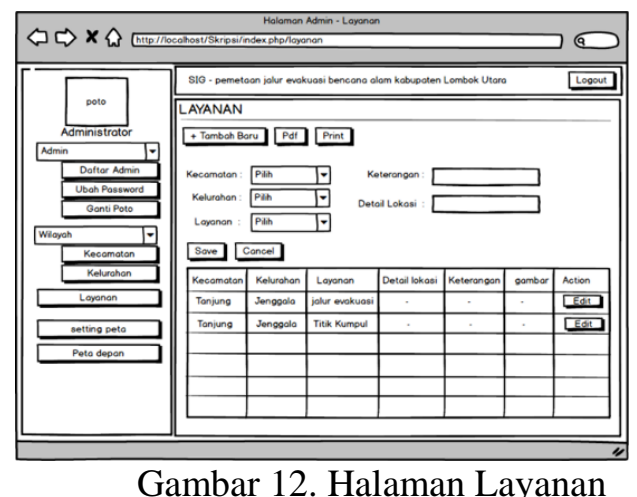

\section{HASIL DAN PEMBAHASAN}

A. Persiapan Implementasi

Pada tahap ini di lakukan beberapa persiapan sebelum melakukan implementasi program. Adapun tahap-tahap yang di lakukan dalam proses ini adalah:

a. Instalasi XAMPP Contol Panel v.3.2.2 di gunakan sebagai database server atau penghubung antara sistem dengan database.

b. Instalasi Sublime Text v.3 di gunakan sebagai text editor pengkodean.

c. Browser (Google Chrome) di gunakan untuk uji coba sistem dan menampilkan antarmuka (Inteface) dari sistem yang di buat.

\section{B. Penjelasan Program}

Menjelaskan tentang tampilan, serta alur dan prosedur program menggunakan flowchart, sesuai dengan rancangan, sebagai berikut:

a. Tampilan Halaman Utama

Halaman yang pertama kali muncul ketika aplikasi di jalankan oleh pengguna maupun administrator. Berikut adalah tampilan halaman utama: 


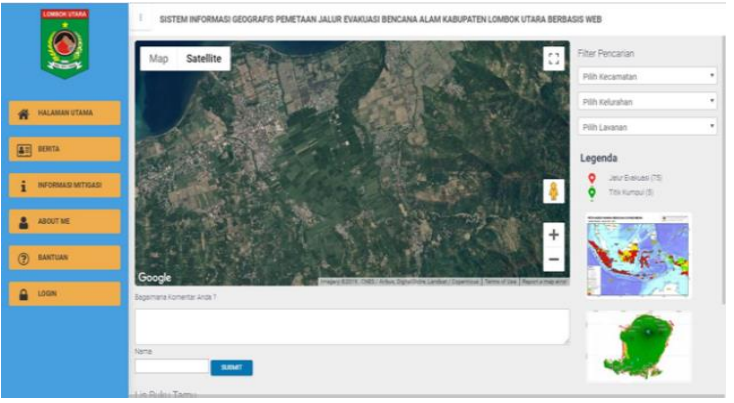

Gambar 13 Tampilan Halaman Utama

b. Tampilan Halaman Berita

Halaman yang muncul ketika pengguna memilih menu beritadengan tampilan sebagai berikut :

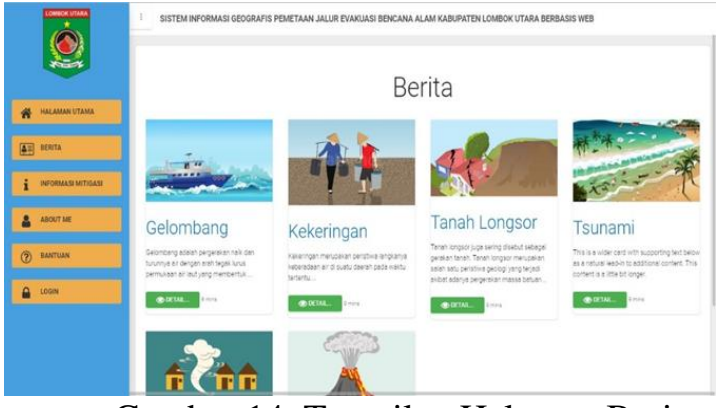

Gambar 14. Tampilan Halaman Berita

c. Tampilan Halaman Informasi Mitigasi

Halaman yang muncul ketika user atau pengguna memilih menu Informasi mitigasi, Hamalan ini berisi tentang mitigasi atau tindakan-tindakan yang perlu di lakukan jika terjadi bencana, di mana informasi-informasi tersebut di buat dalam bentuk gambar sehingga lebih mudah untuk di pahami. Berikut adalah tampilan untuk halaman informasi mitigasi:

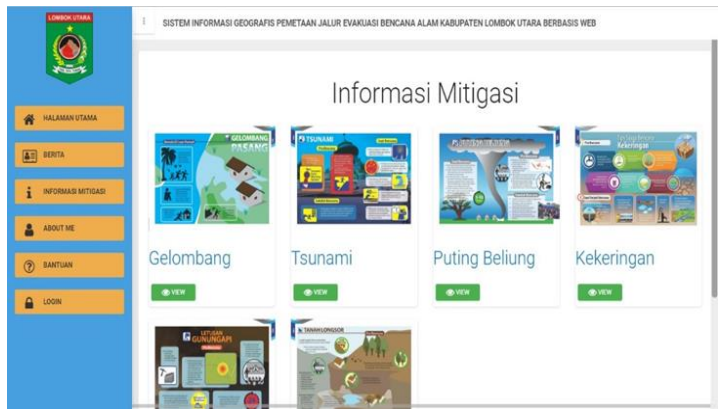

Gambar 15 Tampilan Halaman Informasi Mitigasi

\section{d. Tampilan Halaman Dashbord Admin}

Halaman yang muncul jika Administrator berhasil login ke halaman admin, dengan tampilan sebagai berikut :

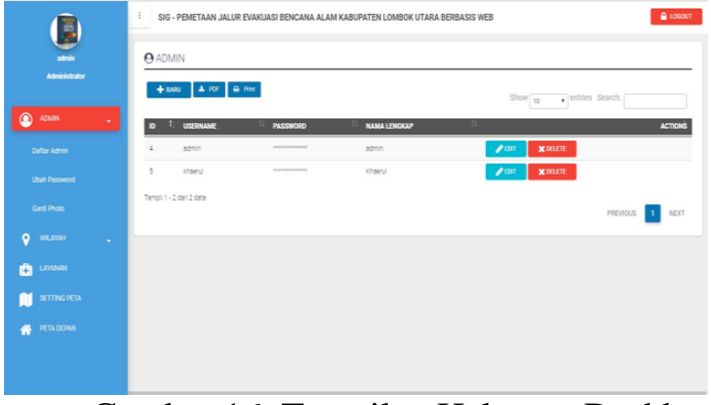

Gambar 16. Tampilan Halaman Dashbor Admin

\section{e. Tampilan Halaman Kecamatan}

Halaman yang muncul jika Administrator memilih menu wilayah kemudian memilih menu kecamatan, di mana pada halaman ini akan menampilkan data-data kecamatan yang ada di Kabupaten Lombok Utara. Berikut adalah tampilan untuk halaman Kecamatan:



Gambar 17. Tampilan Halaman Kecamatan

f. Tampilan Halaman Kelurahan

Halaman yang muncul jika Administrator memilih menu kelurahan, Halaman ini akan menampilkan data-data kelurahan sesuai dengan kecamatan yang ada di Kabupaten Lombok Utara. Berikut adalah tampilan untuk halaman Kelurahan:

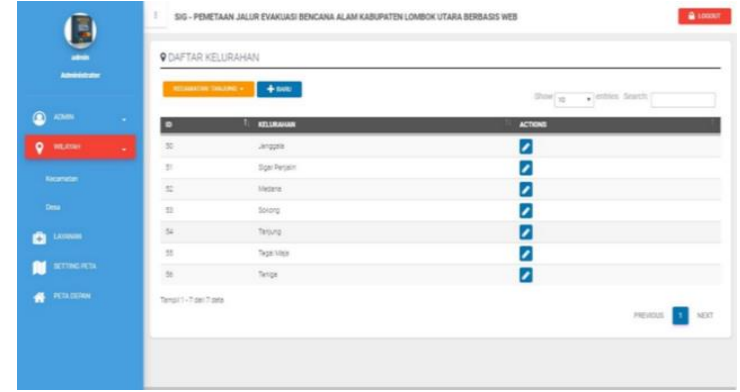

Gambar 18. Tampilan Halaman Kelurahan

g. Tampilan Layanan (Jalur Evakuasi dan Titik Kumpul) 
Halaman yang muncul jika Administrator memilih menu layanan yang berisi inputan untuk jalur evakuasi dan titik kumpul, di mana pada halaman ini berisi data-data jalur evakuasi dan titik kumpul dari setiap kecamatan dan kelurahan yang ada di Kabupaten Lombok Utara.

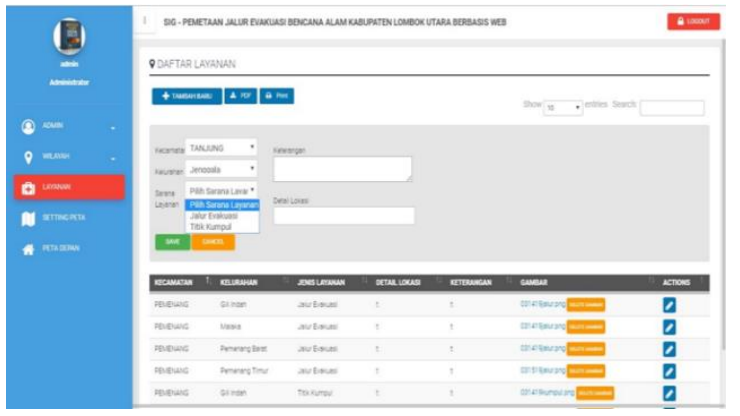

Gambar 19. Tampilan Halaman Layanan

\section{Hasil Pengujian}

Untuk membuktikan kevalidan dari hasil aplikasi, maka penggunaan teknik Pengujian Black-box dilakukan. Tahap pengujian antara lain dilakukan pengujian fungsionalitas untuk fitur-fitur yang disediakan aplikasi.

\begin{tabular}{|c|c|c|c|c|c|c|}
\hline $\begin{array}{c}\mathrm{N} \\
\text { o }\end{array}$ & $\begin{array}{c}\text { Juml } \\
\text { ah } \\
\text { peng } \\
\text { ujia } \\
\mathrm{n}\end{array}$ & $\begin{array}{c}\text { Juml } \\
\text { ah } \\
\text { hasil } \\
\text { diter } \\
\text { ima }\end{array}$ & $\begin{array}{c}\text { Juml } \\
\text { ah } \\
\text { hasil } \\
\text { ditol } \\
\text { ak }\end{array}$ & $\begin{array}{c}\text { Bobo } \\
\text { t } \\
\text { diter } \\
\text { ima - } \\
\text { ditol } \\
\text { ak) }\end{array}$ & $\begin{array}{c}\text { perse } \\
\text { ntase }\end{array}$ & $\begin{array}{c}\text { kateg } \\
\text { ori }\end{array}$ \\
\hline 1 & 9 & 28 & 5 & 23 & $20 \%$ & Baik \\
\hline 2 & 9 & 28 & 5 & 23 & $20 \%$ & Baik \\
\hline 3 & 9 & 28 & 5 & 23 & $20 \%$ & Baik \\
\hline 4 & 9 & 26 & 7 & 19 & $20 \%$ & $\begin{array}{c}\text { Cuku } \\
\text { p } \\
\text { baik }\end{array}$ \\
\hline 5 & 9 & 25 & 8 & 17 & $20 \%$ & $\begin{array}{c}\text { Cuku } \\
\text { p } \\
\text { baik }\end{array}$ \\
\hline
\end{tabular}

\begin{tabular}{|c|c|c|c|}
\hline $\begin{array}{c}\text { Kategori } \\
\text { bobot }\end{array}$ & Kategori & jumlah & $\begin{array}{c}\text { Persentase } \\
\text { keseluruhan }\end{array}$ \\
\hline $26-33$ & $\begin{array}{c}\text { Sangat } \\
\text { baik }\end{array}$ & - & - \\
\hline $20-25$ & Baik & 3 orang & $60 \%$ \\
\hline $15-24$ & $\begin{array}{c}\text { Cukup } \\
\text { baik }\end{array}$ & 2 orang & $40 \%$ \\
\hline $0-14$ & Kurang & - & - \\
\hline
\end{tabular}

Berdasarkan hasil pengujian yang telah di lakukan dari 5 orang, dimana $60 \%$ menyatakan bahwa aplikasi sudah berjalan dengan baik dan sistem cukup lengkap, 40\% menyatakan bahwa aplikasi berjalan cukup baik namun perlu ada penambahan-penambahan fitur lain.

Setelah melakukan pengujian aplikasi maka dapat disimpulkan bahwa pengujian fungsionalitas pada aplikasi ini sudah berjalan sesuai dengan yang diharapkan yaitu berjalan baik atau sukses.

\section{SIMPULAN DAN SARAN}

Dari uraian pada pembahasan, berikut kesimpulan yang dapat dijelaskan seperti : 1).Masyarakat mengetahui jalur evakuasi dan titik kumpul. 2).Sistem memberikan informasi terkait tindakan yang harus dilakukan sebelum dan setalah terjadinya terjadi bencana, 3). Pengujian fungsionalitas dari aplikasi ini sudah berjalan sesuai dengan harapan yaitu berjalan dengan baik.

Sedangkan hal-hal yang perlu diperbaiki dari system yang sedang berjalan adalah sebagai berikut : 1). Mengembangkan aplikasi ini agar dapat di implementasikan menggunakan mobile atau android. 2). Menambahkan polyline atau penghubung antara titik awal dan titik tujuan, atau dalam penelitian ini yaitu titik jalur evakuasi menuju titik kumpul (Rute Perjalanan). 3). Menambahkan metode-metode untuk menentukan jalur terpendek dari lokasi titik awal menuju titik tujuan atau dalam penelitian ini yaitu titik jalur evakuasi menuju titik kumpul. 4).Menyarankan untuk mengembangkan sistem ini dengan berfokus pada semua bencana alam.

\section{UCAPAN TERIMAKASIH}

Trima kasih banyak penulis ucapkan kepada semua pihak khususnya Lembaga penelitian dan Pengabdian kepada Masyarakat (LPPM) Universitas Bumigora, yang telah banyak membantu untuk penyelesain penelitian ini.

\section{REFERENSI}

[1] Nurfaida, "Penggunaan SIG Untuk Pemetaan Jalur Evakuasi Bencana Tsunami Di Desa Tonggolobibi Kecamatan Sojol Kabupaten Donggala," E-Journal Geo-Tadulako UNTAD, vol. Volume 4, no. 1, pp. 1-10, 2016.

[2] R. B. Indonesia, "Risiko bencana indonesia."

[3] A. A. W, "Partisipatif, Jalur Evakuasi, 
Titik Kumpul,” 2014.

[4] A. Adil, "Sistem Informasi Geografis," p. 172, 2017.

[5] A. I. Gufroni, A. N. Rachman, and Y. A. Malik, "Implementasi Google Maps API Dalam Aplikasi Mobile Penghitung Jarak Aman Dari Dampak Kemungkinan Letusan Gunung Galunggung," Semin. Nas. Apl. Teknol. Inf. 2013.Yogyakarta, 15 Juni 2013. ISSN 1907 - 5022, pp. 1216, 2013.

[6] K. Rizki and A. Adil, "Implementasi Google Maps API Berbasis Android untuk Lokasi Fasilitas Umum di Kabupaten Sumbawa," J. MATRIK, vol. 17, no. 2, pp. 34-44, 2018.

[7] R. S. Pressman, Software-Engineering 7th ED by Roger S. Pressman. 2012.

[8] W. Suryn, Software Quality Engineering: A Practitioner's Approach, vol. 9781118592. 2014.

[9] B. Bruegge and E. Riedel, A geographic environmental modeling system: Towards an object-oriented framework, vol. 821 LNCS. 1994.

[10] A. Adil, "Perancangan Spasial Pengembangan Potensi Produk Kerajinan berbasis Pemukiman di Taman Nasional Komodo," MATRIK J. Manajemen, Tek. Inform. dan Rekayasa Komput., vol. 18, no. 1[1] A. Adil, "Perancangan Spasial Pengembangan Potensi Produk Kerajinan berbasis Pemukiman di Taman Nasional Komodo," MATRIK J. Manajemen, Tek. Inform. dan Rekayasa Komput., vol. 18, number 1 , pp. 50-57, 2018., pp. 50-57, 2018.

[11] T. Work et al., "Object Oriented Modeling and Design using UML," no. Semester IV, pp. 5-7. 